\title{
Plasma Enhanced Chemical Vapour Deposition (PECVD) at Atmospheric Pressure (AP) of Organosilicon Films for Adhesion Promotion on $\mathrm{Ti}_{15} \mathrm{~V}_{3} \mathrm{Cr}_{3} \mathrm{Sn}_{3} \mathrm{Al}$ and $\mathrm{Ti}_{6} \mathrm{Al}_{4} \mathrm{~V}$
}

\author{
Jana Haag $^{1 *}$, Tobias Mertens ${ }^{1}$, Max Kolb ${ }^{1}$, Liliana Kotte ${ }^{2}$ and Stefan Kaskel ${ }^{2}$ \\ 1. Airbus Group Innovations, Dept. TX2, 81663 Munich, Germany \\ 2. Fraunhofer IWS, Winterbergstrasse 28, 01219 Dresden, Germany
}

\begin{abstract}
The recent generation of aircraft is manly built out of CRFP (Carbon fiber reinforced plastic). To ensure galvanic compatibility Titanium alloys are used at connecting points to metallic structures. The increased use of Titanium alloys due to their good mechanical properties has highlighted the need for structural bonding as joining method to combine Titanium with CFRP. However, long-term stable adhesion on Titanium is still an issue. Currently mainly wet-chemical processes are applied to improve adhesion on Titanium alloys. Since wet-chemical treatments often comprise the use of hazardous chemicals dry environmentally friendly surface functionalization processes are pushed more into focus. PECVD (Plasma enhanced chemical vapour deposition) at AP (Atmospheric pressure) seems to be favorable for the deposition of silicon dioxide films as an adhesion promoter layer. In the present work, the deposition of silicon dioxide adhesion layer (from HMDSO (Hexamethyldisiloxane) as precursor) on titanium alloys is described for a linearly extended and scalable DC arc plasma source (LARGE). The wedge test is used to evaluate the adhesion properties of coated titanium samples in comparison to the standard used NaTESi anodizing process. The results show that the atmospheric pressure plasma process leads to good long-term durability and to high bonding strength which is comparable to the used standard pre-treatments.
\end{abstract}

Key words: Atmospheric pressure PECVD (Plasma enhanced chemical vapour deposition), plasma surface treatment, silicon dioxide films, titanium alloys, adhesion layers.

\section{Introduction}

In the aerospace industry new design concepts offering weight savings are high in demand. In the recent generation of aircraft (e.g. Airbus 350 XWB, Boeing 787), composite materials have shown new perspectives in terms of structural efficiency and performance. In a fast-paced environment under threat from new market entrants and technology disruptions, competitiveness and operational excellence new technologies have to be developed which give our products additional values like new light weight designs. In an economically and technologically ever-accelerating environment the customers (e.g.

\footnotetext{
*Corresponding author: Jana Haag, Dipl-Chem, research field: atmospheric pressure plasma pre-treatment of titanium and CFRP. E-mail: jana.haag@airbus.com.
}

airlines) expect that new technologies lead to less fuel burn without any impact on comfort. To keep this target new surface treatments like atmospheric pressure plasma are necessary to meet the requirements from the customers and to increase the efficiency in manufacturing.

It is well known that in the aerospace industry titanium materials exhibit critical issues in regard to long-term stable adhesion. Therefore composite titanium hybrid joints can only be realized by riveting. Adhesive bonding is seen to be the key to realize weight saving hybrid structures. However for this application surface treatments have to be developed to ensure long-term stable adhesion on titanium and composite materials.

For improving the adhesion on titanium various wet-chemical surface treatment methods which are 
partially based on environmentally hazardous compounds are used. PECVD (Plasma enhanced chemical vapor deposition) of organosilicon films at atmospheric pressure for adhesion promotion seems to be an alternative to these hazardous or manual methods.

During the last years, depositing of polymer-like organosilicon films or inorganic $\mathrm{SiO}_{\mathrm{x}}$-like films by plasma polymerization technology have been utilized in a wide range of applications, such as protective coatings, adhesion promoters, biomedical materials, electronic and optical devices [1]. This is mainly owing to the fact that the functionality and important properties of plasma deposited layer can be determined by the nature of the used vapor precursors and deposition parameters [2, 3]. Among the wide variety of possible precursors for plasma-polymerization, the organosilicon monomer HMDSO (Hexamethyldisiloxane) is perhaps the most common and widely utilized product. HMDSO is non-toxic, non-flammable and easy to handle [4]. Moreover, HMDSO has high deposition rate and the ability to control the structure and properties of the polymerized films by varying deposition conditions [5].

In this paper, a linearly extended and scalable DC arc plasma source (LARGE) is used for the deposition of silica layers on $\mathrm{Ti}_{15} \mathrm{~V}_{3} \mathrm{Cr}_{3} \mathrm{Sn}_{3} \mathrm{~V}$ and $\mathrm{Ti}_{6} \mathrm{Al}_{4} \mathrm{~V}$. The injection of the precursor is carried out by a remote gas feeding system made of BN (Boron Nitride). In the first section of the paper, the investigation of surface morphology and chemical composition after acidic etching are described. In this stage the characterization of deposited silicone dioxide film which is evaluated for HMDSO as precursor is executed. The second part covers the investigation of the long-term durability of bonded titanium samples in hot-wet condition.

Adhesive bonding tests have been performed in comparison to the wet chemical treatments like anodizing processes. The influence of the different plasma treatment parameters on adhesion properties was evaluated by the wedge test.

\section{Materials and Methods}

\subsection{Materials}

For this investigation the titanium alloys $\mathrm{Ti}_{15} \mathrm{~V}_{3} \mathrm{Cr}_{3} \mathrm{Sn}_{3} \mathrm{Al}$ AMS4914 and $\mathrm{Ti}_{6} \mathrm{Al}_{4} \mathrm{~V}$ AMS4911 are used. In $\mathrm{Ti}_{15} \mathrm{~V}_{3} \mathrm{Cr}_{3} \mathrm{Sn}_{3} \mathrm{Al}$ alloy, the main elements are $\beta$ - stabilizer such as vanadium and chromium. Tin is considered a neutral element since it does not strongly promote phase stability, it retards the rates of transformation and is useful as strengthening agent [6]. The $\mathrm{Ti}_{6} \mathrm{Al}_{4} \mathrm{~V}$ alloy belongs to $\alpha+\beta$ - titanium alloys due to the main alloying elements the $\alpha$-phase-stabilizer aluminum and the $\beta$-phase-stabilizer vanadium $[7,8]$.

For the wedge test investigations specimens with an edge length of $150 \mathrm{~mm}$ and a thickness of $2.0 \mathrm{~mm}$ are used. Analytical investigations are conducted on polished samples $(\mathrm{Ra}=10 \mathrm{~nm}$, measured by DektakTX Bruker, Germany) with the dimension of $25 \times 25 \mathrm{~mm}^{2}$.

\subsection{Surface Treatment}

All titanium samples are processed with the same steps for cleaning and texturing the surface prior to pre-treatment steps. The samples were cleaned with the alkaline cleaner using P3 almeco 18 (Henkel AG $\&$ Co. KGaA, Düsseldorf, Germany) at $65 \pm 3{ }^{\circ} \mathrm{C}$ for 15 min. Subsequently, the samples were alkaline etched with Turco 5578 (Henkel AG \& Co. KGaA, Düsseldorf, Germany) at $95 \pm 3{ }^{\circ} \mathrm{C}$ for 5 min using a concentration of $500 \mathrm{~g} / \mathrm{L}$.

\subsection{NaTESi Anodizing}

The NaTESi pre-treatment of titanium for structural bonding were developed by Matz [9]. This process is used in this investigation as a reference to atmospheric pressure plasma deposition. The NaTESi anodisation was carried out using a three-electrode configuration with titanium sample as cathode. According to the investigation of Matz, the process is performed at $30 \pm$ 
$2{ }^{\circ} \mathrm{C}$ and $10 \mathrm{~V}$ for $15 \mathrm{~min}$. The electrolyte contains $300 \mathrm{~g} / \mathrm{L}$ sodium hydroxide, $65 \mathrm{~g} / \mathrm{L}$ Na-tartrate, $30 \mathrm{~g} / \mathrm{L}$ EDTA (Ethylendiamintetraacetic) and $6 \quad \mathrm{~g} / \mathrm{L}$ Natriumsulfit.

\subsection{Plasma Treatment}

For the nanometer-thin silicon dioxide film deposition the LARGE plasma source with linearly extended and stabilized DC arc plasma at atmospheric pressure is used. The principle of this PECVD process and the detailed description of the plasma source is given in previous publications [3, 10-12]. The silicon dioxide layer deposition presented in this paper is carried out with a $150 \mathrm{~mm}$ long arc and HMDSO as precursor. The precursor was heated up to $130{ }^{\circ} \mathrm{C}$. For the precursor injection a remote gas feeding system made from $\mathrm{BN}$ is installed in front of the LARGE plasma source to avoid the contamination. The titanium samples were moved in front of the source at 20, 40 and $60 \mathrm{~mm}$ working distances. Depending on the cycles number the defined thickness of the plasma layer can be deposited on the surface. The process parameters are given in Table 1.

\subsection{Surface Characterization}

The chemical composition and the surface morphology of the initial oxide layer after acidic etching were investigated by means of SEM (Scanning electron microscope) using a Jeol JSM-6320F field emission scanning electron microscope (Jeol, Tokyo, Japan) in combination with energy dispersive $\mathrm{x}$-ray analysis (EDX). Samples have been prepared by metallographic sectioning technique.
The grinding step has been carried out with $\mathrm{SiC}$ (Silicon carbide) abrasive paper by decreasing the abrasive particle size from 80 to 4,000 grit. Subsequently, the samples were rough polished with 6-micron diamond followed by a 1-micron diamond on low napped polishing cloths. For the final polishing step the low napped polishing pads with colloidal silica were used. After polishing procedure the samples were chemical etched to optically enhance microstructural features such as grain size and phase features. The etching mixture consists of $960 \mathrm{~mL}$ $\mathrm{H}_{2} \mathrm{O}, 25 \mathrm{~mL} \mathrm{HNO}_{3}(65 \%)$ and $15 \mathrm{~mL} \mathrm{HF}(40 \%)$. The exposure time to chemical etchant was $15 \mathrm{~s}$. For investigation of the deposited thin silicone dioxide film cross sectioning is performed by FIB (Focused ion beam) thinning at the NMI (Naturwissenschaftliches und Medizinisches Institute) Tübingen. The schematically drawing of the FIB cross-section preparation is given in Fig. 1.

For FIP cross-sections, the sample pieces were glued on aluminum sample plate and electrically contacted with conductive silver. Before carrying out the FIB cross-sections a thin Pt protective strip has been deposited to the sample surface by means of electron beam (dark red). Then, in order to avoid etching of the surface during the ion beam deposition, thick Pt protective strip has been deposited by means of ion beam (bright red).

\subsection{Test Methods}

In order to evaluate the bonding strength the wedge test according to the German standard DIN 65448 was employed. The test combines mechanical and

Table 1 Process parameter.

\begin{tabular}{ll}
\hline Process parameters & Value \\
\hline Plasma gas & $70 \mathrm{SLM} / \mathrm{min} \mathrm{Ar}+50 \mathrm{SLM} / \mathrm{min} \mathrm{N}_{2}+160 \mathrm{SLM} /$ min compressed air \\
Remote gas & $40 \mathrm{SLM} / \mathrm{min} \mathrm{N}_{2}+40 \mathrm{SLM} / \mathrm{min}_{2}$ \\
Precursor & $20 \mathrm{~g} / \mathrm{h} \mathrm{HMDSO}$ \\
Working distance & 2 to $6 \mathrm{~cm}$ \\
Working width & $150 \mathrm{~mm}$ \\
Current & $75 \mathrm{~A}$ \\
Substrate velocity & $10 \mathrm{~m} / \mathrm{min}$ \\
\hline
\end{tabular}




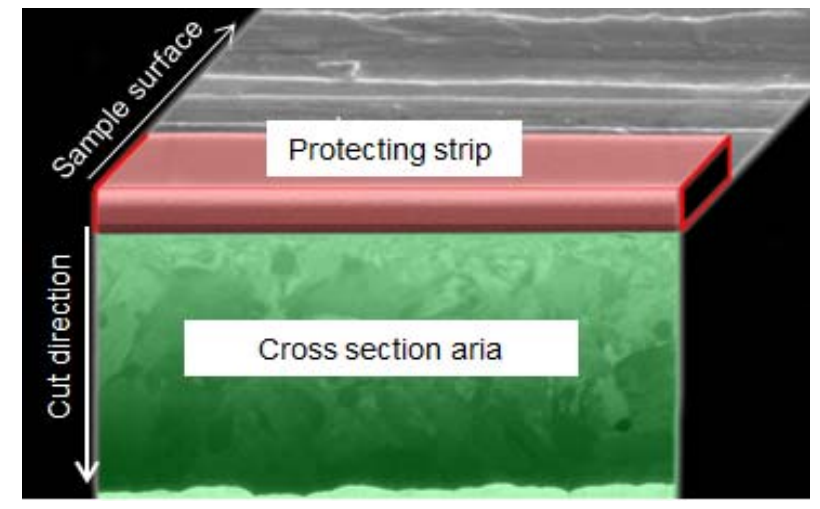

Fig. 1 Schematically drawing of the FIB cross section.

hydrothermal loads. After the pre-treatment two sheets are bonded with an aerospace certify epoxy-based adhesive FM $73 \mathrm{M}$ (cured in an autoclave at $120{ }^{\circ} \mathrm{C}$ and a pressure of $0.25 \mathrm{MPa}$ ). The matrix of the FM 73 $\mathrm{M}$ is composed out of DGEBA (diglycidylether of bisphenol-A) and a hardening component 2, 4-tolyl-1, 1-dimethylurea. Stripes with the dimensions of $25 \times$ $150 \mathrm{~mm}^{2}$ are employed for testing. To start the crack propagation a stainless steel wedge is introduced into the bondline. Subsequently the samples are subjected to a hot-wet environment $\left(50{ }^{\circ} \mathrm{C}, 95 \% \mathrm{rH}\right)$ for $500 \mathrm{~h}$. The growth of the crack, initiated by the wedge is microscopically monitored with times after $1.25,24$, 48, 96, 168, 336 and $500 \mathrm{~h}$.

\section{Results and Discussion}

\subsection{Investigation of Surface Morphology and Chemical Composition after Etching}

The morphology and the chemical composition of the surface after alkaline etching step have an influence on the growth of the plasma layer during deposition. For the analytical investigations of the titanium alloys $\mathrm{Ti}_{15} \mathrm{~V}_{3} \mathrm{Cr}_{3} \mathrm{Sn}_{3} \mathrm{Al}$ and $\mathrm{Ti}_{6} \mathrm{Al}_{4} \mathrm{~V}$ metallographic sections were prepared. The surfaces were grinded and polished. Subsequently the metallographic sections were etched with $\mathrm{HF} / \mathrm{HNO}_{3} / \mathrm{H}_{2} \mathrm{O}$ mixture to evaluate the alloy structure with their grain boundaries and precipitations. Fig. 2a shows the microsection of $\mathrm{Ti}_{6} \mathrm{Al}_{4} \mathrm{~V}$ after etching. The titanium alloy $\mathrm{Ti}_{6} \mathrm{Al}_{4} \mathrm{~V}$ exhibits a large amount of micro roughness. The typical $\alpha+\beta$ - microstructure with bright body-centered cubic $\beta$-phase precipitations at the closed-packed hexagonal $\alpha$ - phase grain boundaries is visible. Fig. $2 \mathrm{a}$ exhibits a $\alpha+\beta$ titanium alloy bimodal structure with equiaxed primary $\alpha$ grains (dark) and lamellar $\alpha+\beta$ colonies, and transformed $\beta$ (bright spots).

In contrast to Fig. 2a, the cross section of the titanium alloy $\mathrm{Ti}_{15} \mathrm{~V}_{3} \mathrm{Cr}_{3} \mathrm{Sn}_{3} \mathrm{Al}$ (Fig. 2b) shows coarsely crystalline structure of $\beta$-grains with two different orientations at the grain boundary. Fig. 3 a and $3 b$ feature the SEM micrographs and the position of the EDX line scans for both titanium alloys. The SEM micrograph of $\mathrm{Ti}_{6} \mathrm{Al}_{4} \mathrm{~V}$ exhibits $\beta$-segregations which are associated with $\alpha$-segregations (Fig. 2a). In this area $\alpha$-phase stabilized aluminum is depleted and $\beta$-phase stabilized vanadium is enriched. This phenomenon is well visible in the EDX spectrum. At the $\beta$-precipitations the vanadium content (yellow line) increases and the aluminum content (blue line) decreases. The EDX line scan of $\beta$-titanium alloy $\mathrm{Ti}_{15} \mathrm{~V}_{3} \mathrm{Cr}_{3} \mathrm{Sn}_{3} \mathrm{Al}$ (Fig. 3 b) shows a homogeneous $\beta$ structure without any significant changes in the concentration of the alloying elements.

\subsection{Investigation of the Deposited Silicone Dioxide Layer}

To determine the morphology and the chemical composition of the deposited silicon dioxide layer on both alloys, SEM and EDX were employed to characterize the coating. The cross sections were prepared by FIB technology. Both alloys were treated with the same parameters: $4 \mathrm{~cm}$ working distance and a $150 \mathrm{~nm}$ nominal silicone oxide layer thickness. As precursor Hexamethyldisiloxane (HMDSO) was used.

Fig. 4 a features the extraction area of the FIB lamella. The lamella was taken from a $\mathrm{Ti}_{6} \mathrm{Al}_{4} \mathrm{~V}$ sample after alkaline etching and silicon dioxide film deposition. In Fig. 4 b, SEM micrograph of the FIB lamella was shown. It demonstrates that the deposited plasma layer was very porous with a film thickness of 


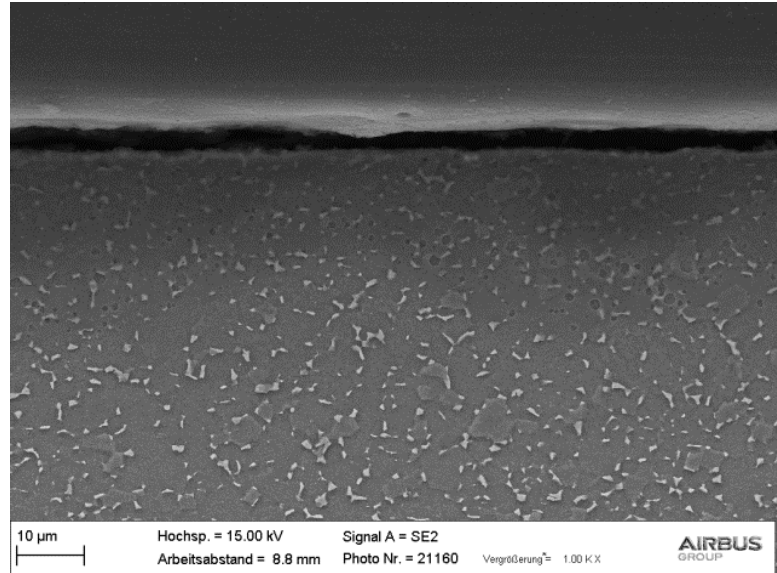

(a)

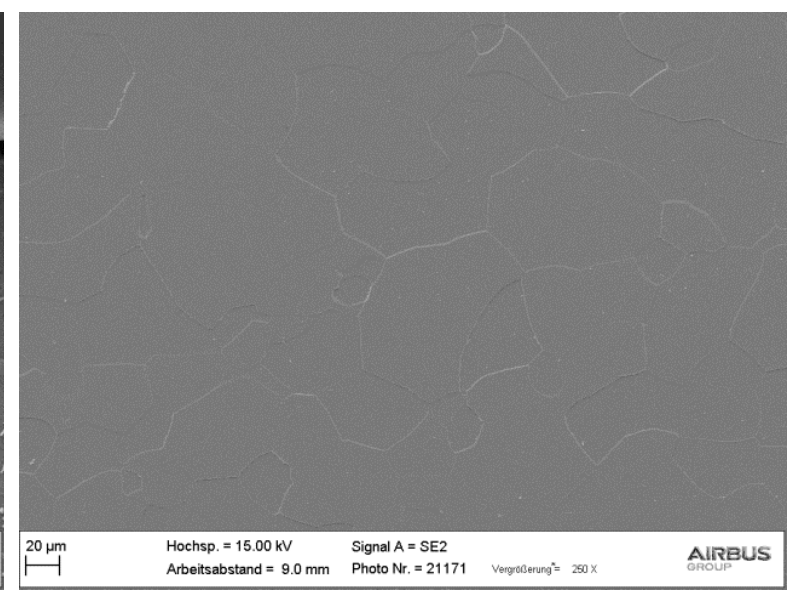

(b)

Fig. 2 SEM micrograph of a metallographic section after etching with $\mathrm{HF} / \mathrm{HNO}_{3} / \mathrm{H}_{2} \mathrm{O}$ mixture: (a) $\mathrm{Ti}_{6} \mathrm{Al}_{4} \mathrm{~V}$ and (b) $\mathrm{Ti}_{15} \mathrm{~V}_{3} \mathrm{Cr}_{3} \mathrm{Sn}_{3} \mathrm{Al}$.

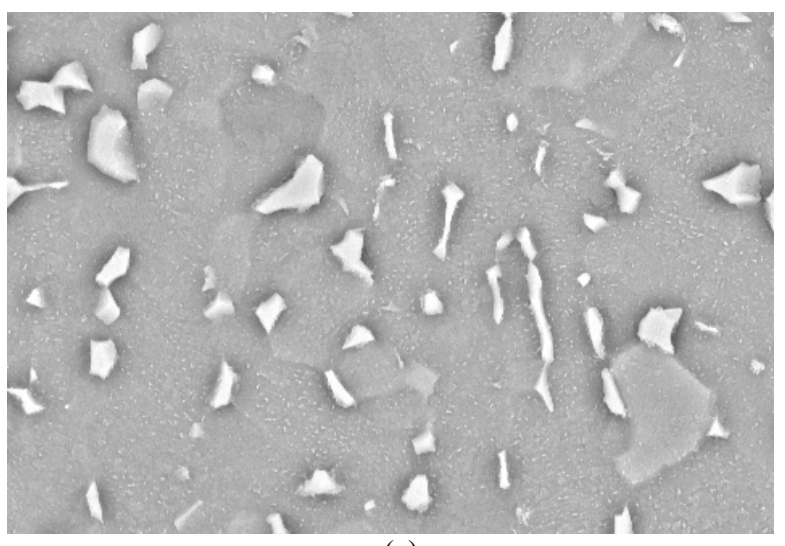

(a)

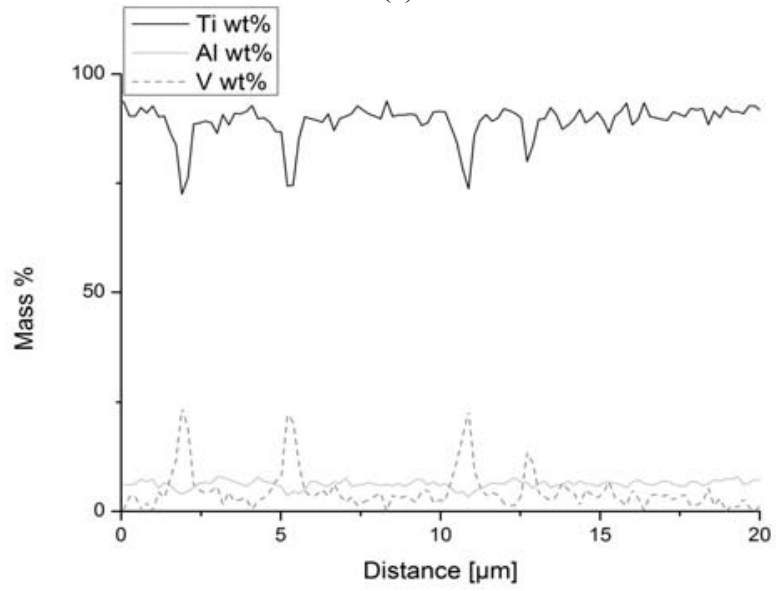

(c)

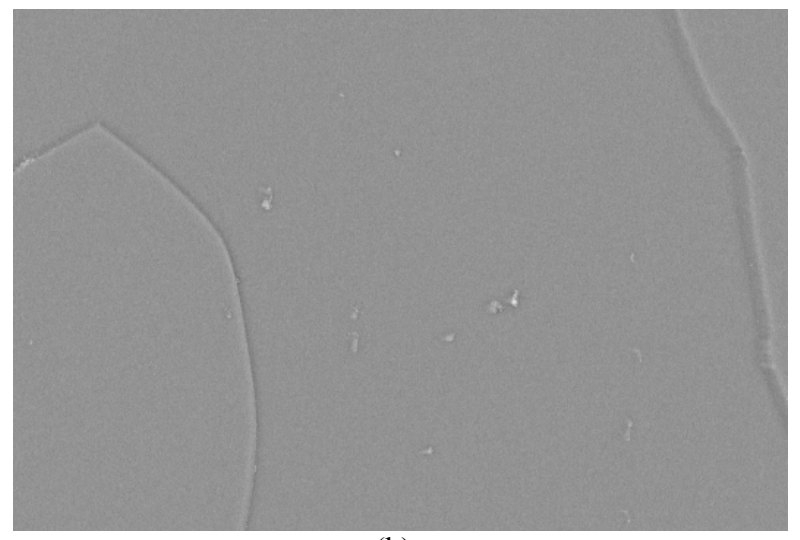

(b)

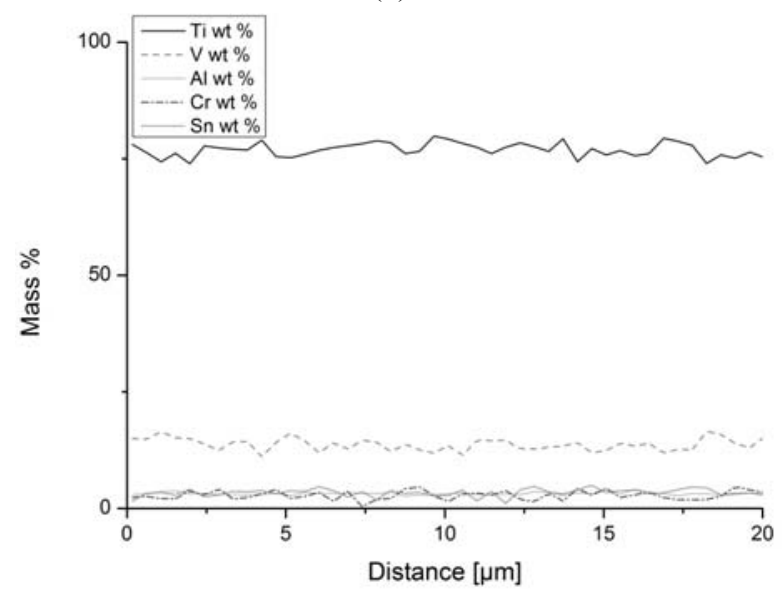

(d)

Fig. $3 \mathrm{SEM}$ micrograph of the etched $\left(\mathrm{HF} / \mathrm{HNO}_{3} / \mathrm{H}_{2} \mathrm{O}\right.$ mixture) titanium with indicated line scan: (a) $\mathrm{Ti}_{6} \mathrm{Al}_{4} \mathrm{~V}$, (b) $\mathrm{Ti}_{15} \mathrm{~V}_{3} \mathrm{Cr}_{3} \mathrm{Sn}_{3} \mathrm{Al}$, (c) features the results of the EDX line scan for the alloy $\mathrm{Ti}_{6} \mathrm{Al}_{4} \mathrm{~V}$ and (d) for the alloy $\mathrm{Ti}_{15} \mathrm{~V}_{3} \mathrm{Cr}_{3} \mathrm{Sn}_{3} \mathrm{Al}$.

app. $95 \mathrm{~nm}$. The interface between the substrate and the plasma layer is structured due to the large amount of micro roughness caused by the alkaline etching (Fig. 8c). This could be the reason for the irregular nucleation on the surface during the HMDSO deposition. Since the titanium oxide layer was structured on several scales, the layer growth during plasma deposition is inhomogeneous. 


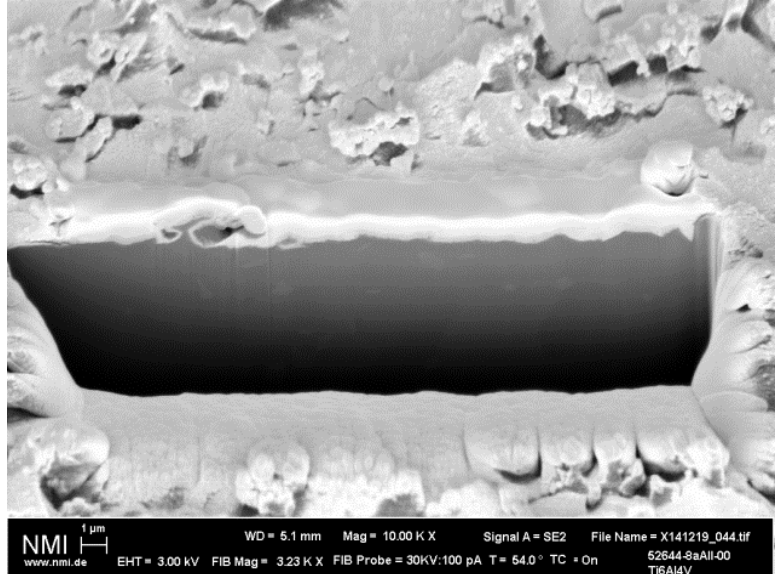

(a)

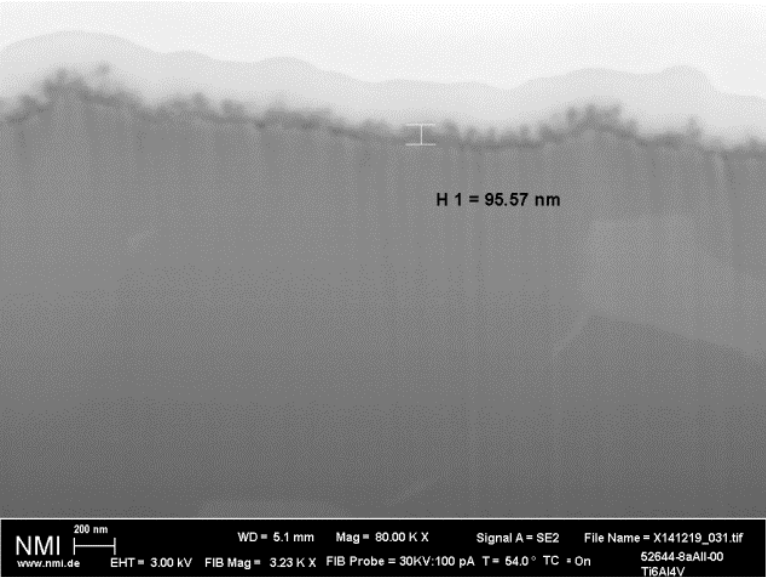

(b)

Fig. 4 (a) Extraction area of FIB lamella $\left(\mathrm{Ti}_{6} \mathrm{Al}_{4} \mathrm{~V}\right.$ sample) after alkaline etching and subsequent plasma deposition from HMDSO; (b) SEM micrograph of the extracted lamella with indicate layer thickness (side view).

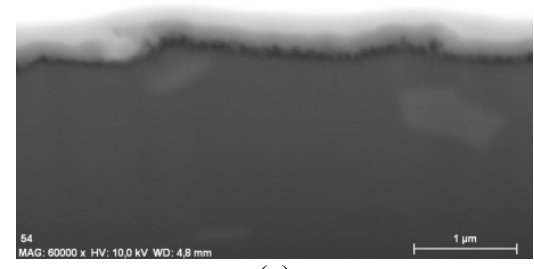

(a)

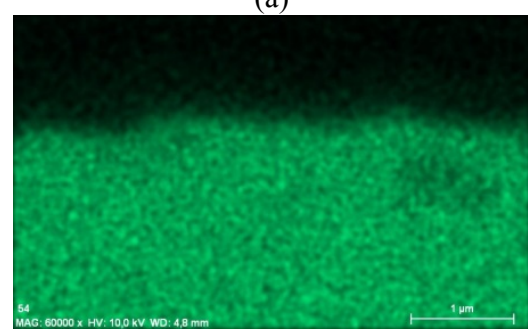

(d)

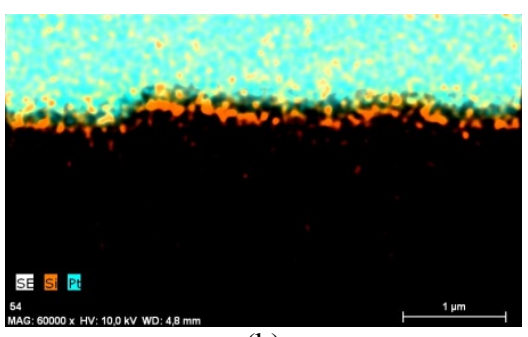

(b)

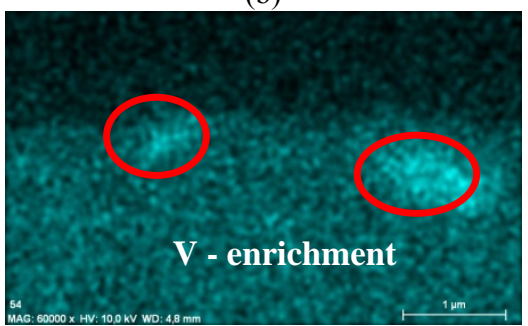

(e)

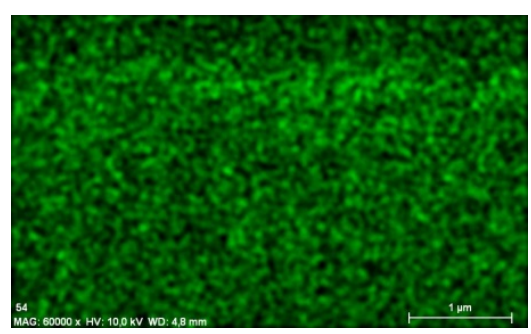

(c)

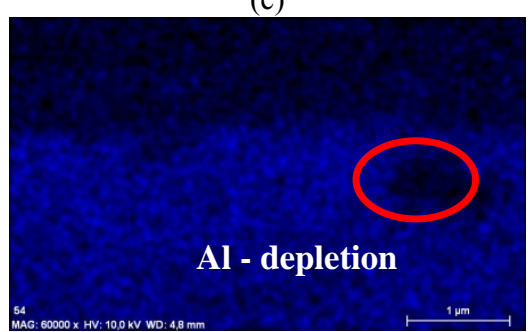

(f)

Fig. 5 (a) SEM micrograph of the extracted lamella with deposited plasma layer on $\mathrm{Ti}_{6} \mathrm{Al} \mathrm{I}_{4} \mathrm{~V}$; EDX mapping on the extracted lamella with the distribution of the elements (b) Si and Pt, (c) O, (d) Ti, (e) V and (f) Al.

Beside the morphology investigations the element distribution within the extracted lamella was measured by EDX. The result of the element mapping is shown in Fig. 5. Fig. 5b exhibits the distribution of Si. It is obvious that the non-homogeneous silicone distribution could be attributed to the observed open porous HMDSO layer. The amount of Oxygen is homogenously scattered in the lamella. Since the plasma layer consists out of $\mathrm{SiO}_{\mathrm{x}}$, the element $\mathrm{Ti}$ can only be found in the substrate and the oxide layer. Within the lamella $\beta$-precipitations could be found. In line with surface EDX measurement the $\beta$-phases feature an enrichment of Vanadium and a depletion of
Aluminum (Fig. 5e and 5f).

In addition to the investigations on $\mathrm{Ti}_{6} \mathrm{Al}_{4} \mathrm{~V}$ the morphology and chemical composition on $\mathrm{Ti}_{15} \mathrm{~V}_{3} \mathrm{Cr}_{3} \mathrm{Sn}_{3} \mathrm{Al}$ is determined. Likewise to $\mathrm{Ti}_{6} \mathrm{Al}_{4} \mathrm{~V}$ a lamella was extracted by FIB after alkaline etching and deposition of a plasma layer.

Fig. 6a features the SEM micrograph of the area where the FIB lamella was extracted. In Fig. 6 b, the side view of the FIB lamella is shown. It demonstrates that the plasma layer is very homogeneous and compact with the thickness of app. $48 \mathrm{~nm}$. The interface between the plasma layer and the substrate shows any macro roughness due to the smooth surface 

Organosilicon Films for Adhesion Promotion on $\mathrm{Ti}_{15} \mathrm{~V}_{3} \mathrm{Cr}_{3} \mathrm{Sn}_{3} \mathrm{Al}$ and $\mathrm{Ti}_{6} \mathrm{Al}_{4} \mathrm{~V}$

after alkaline etching (Fig. 8d). The different layer growth during plasma deposition is attributed to the difference in the initial oxide layer morphologies.

Fig. 7 shows the element distribution after plasma deposition on $\mathrm{Ti}_{15} \mathrm{~V}_{3} \mathrm{Cr}_{3} \mathrm{Sn}_{3} \mathrm{Al}$. The EDX element map of silicone (Fig. 7b) shows a homogeneous

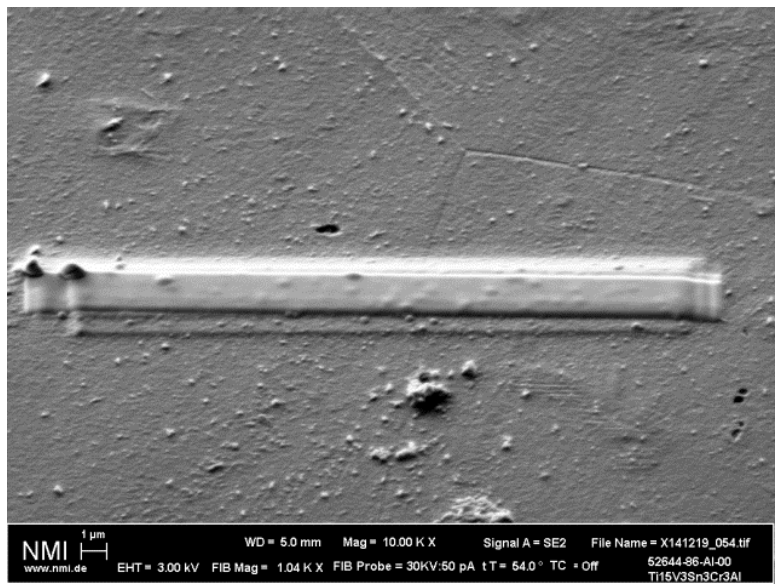

(a) distribution in the plasma layer which is in contrast to the layer on $\mathrm{Ti}_{6} \mathrm{Al}_{4} \mathrm{~V}$. A small enrichment of oxygen can be determined due to the $\mathrm{SiO}_{\mathrm{x}}$ film formd on the surface. The nucleation during the HMDSO deposition occurs uniformly an this leads to a homogenous and compact layer.

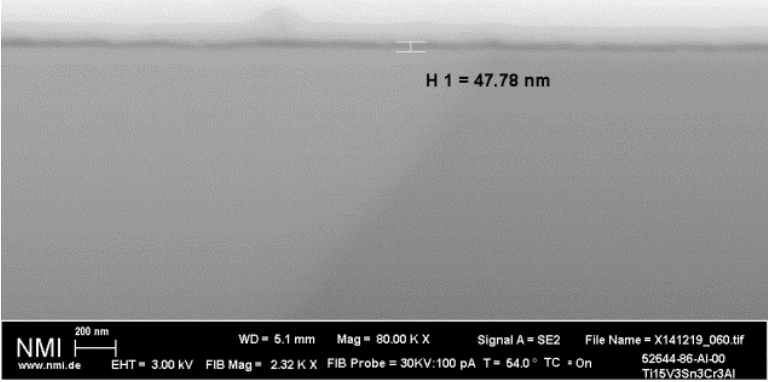

(b)

Fig. 6 (a) Extraction area of FIB lamella $\left(\mathrm{Ti}_{15} \mathrm{~V}_{3} \mathrm{Cr}_{3} \mathrm{Sn}_{3} \mathrm{Al}\right.$ sample) after alkaline etching and subsequent plasma deposition from HMDSO; (b) SEM micrograph of the extracted lamella with indicate layer thickness (side view).

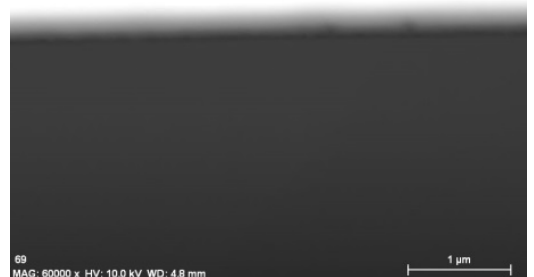

(a)

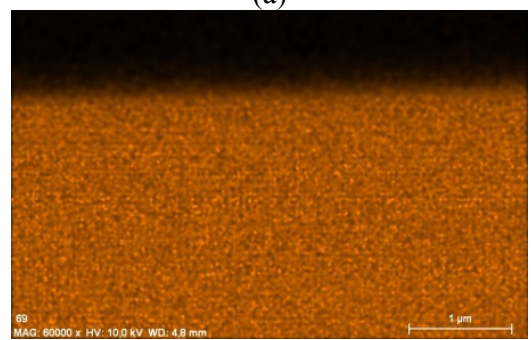

(d)

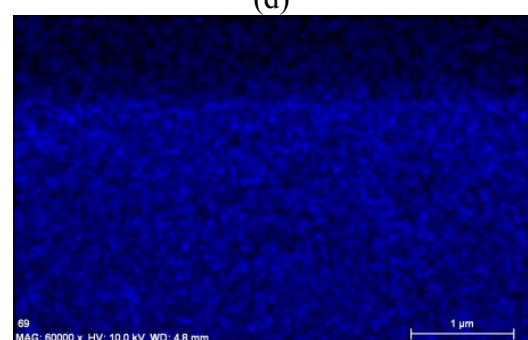

(g)

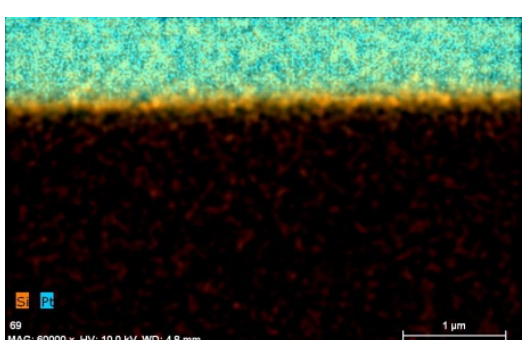

(b)

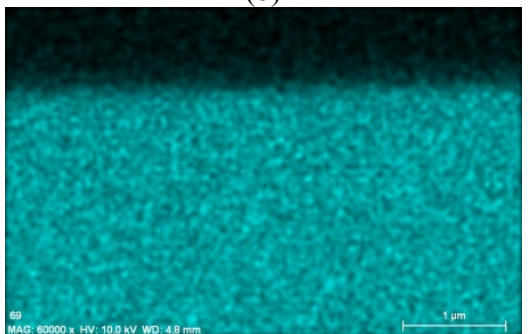

(e)

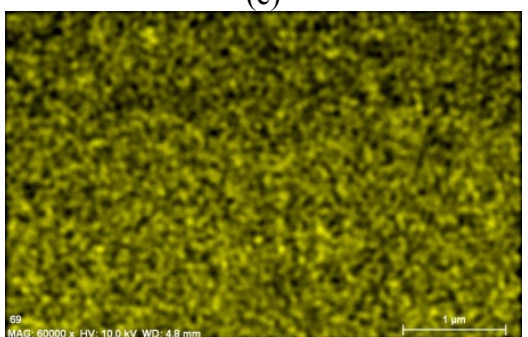

(h)

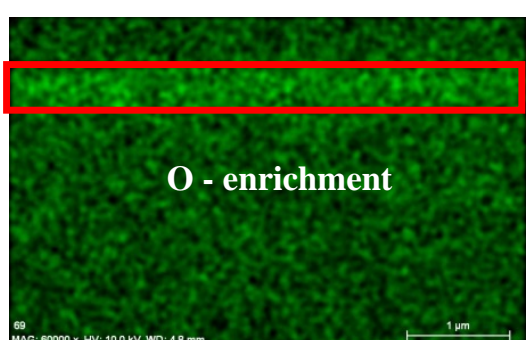

(c)

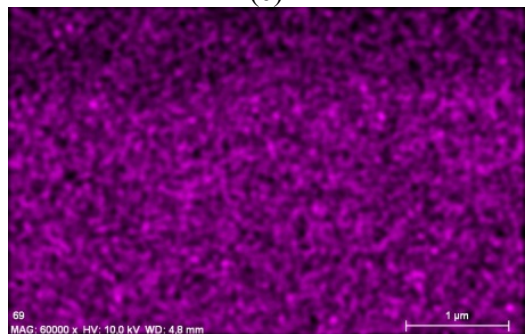

(f)

(i)

Fig. 7 (a) SEM micrograph of the extracted lamella with deposited plasma layer on $\mathrm{Ti}_{15} \mathrm{~V}_{3} \mathrm{Cr}_{3} \mathrm{Sn}_{3} \mathrm{Al}$; EDX mapping on the extracted lamella with the distribution of the elements (b) Si and Pt, (c) O, (d) Ti, (e) V, (f) Cr, (g) Al, (h) Sn. 
Fig. 7d-7h demonstrate homogenous destribution of the alloying elements without any enrichments or depletions.

As mentioned above, the different thickness and homogeneity of the deposited silicone dioxide layer on different titanium alloys depend on the morphology of the etched layer. An epitaxial film growth described in the literature $[13,14]$ is assumed for both alloys. The simplified structure of the different layers created on the two different titanium substrates after alkaline etching step and HMDSO plasma deposition is illustrated schematically in Fig. 8. Moreover SEM micrographs in Fig. 8c and 8b exhibit the different surface morphologies obtained after treatment using Turco 5578. $\mathrm{Ti}_{15} \mathrm{~V}_{3} \mathrm{Cr}_{3} \mathrm{Sn}_{3} \mathrm{Al}$ shows a very smooth surface in comparison to

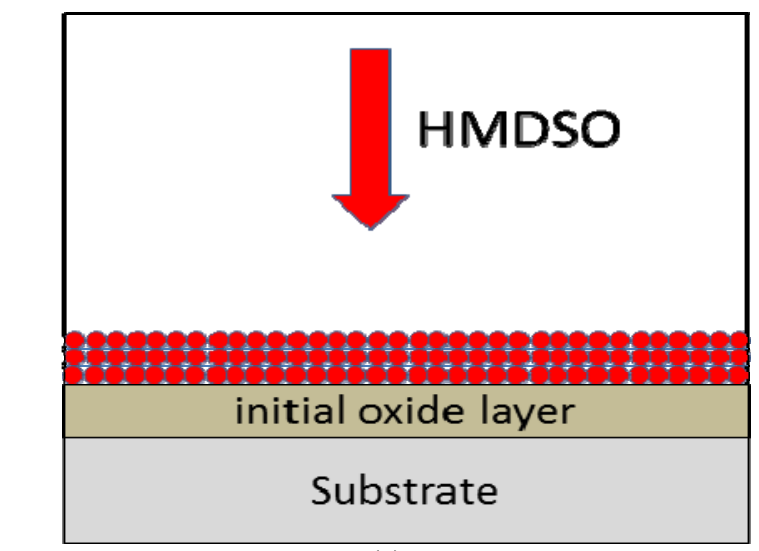

(a)

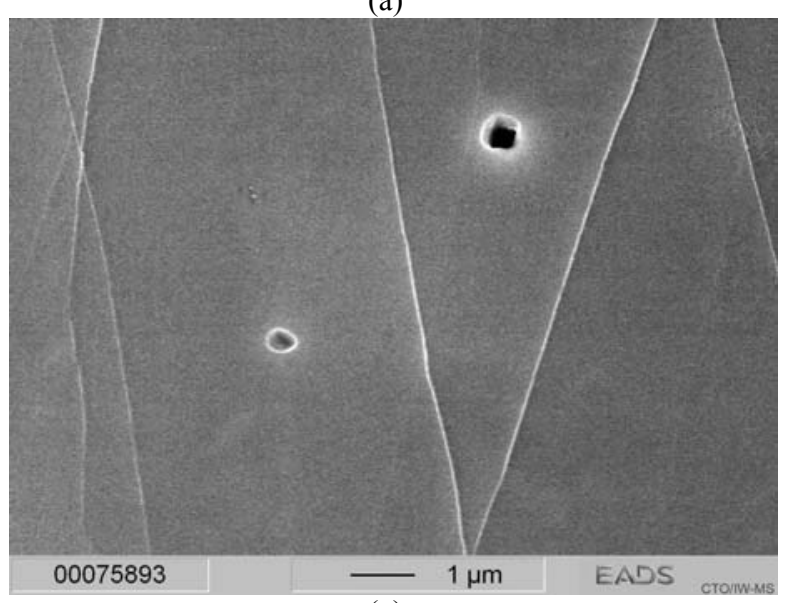

(c)
$\mathrm{Ti}_{6} \mathrm{Al}_{4} \mathrm{~V}$ alloy. This difference in the degree of micro roughness after alkaline etching has an impact on the morphology and the film formation during the plasma process. The impact on the film formation is schematically shown in Fig. 8a and 8b. The plasma film derived on the initial oxide layer $\left(\mathrm{Ti}_{15} \mathrm{~V}_{3} \mathrm{Cr}_{3} \mathrm{Sn}_{3} \mathrm{Al}\right)$, without any micro roughness, leads to a homogeneous surface (red circles in Fig. 8a). In contrast, the micro structured surface of the initial oxide layer on TiAl6V4 causes inhomogeneous and open porous HMDSO layer. The nano-morphology (Fig. 9) and the thickness of the deposited plasma layer are the same in both cases and is app. $50 \mathrm{~nm}$ at a working distance of $6 \mathrm{~cm}$. But the micro morphology of the plasma layer depends on the initial oxide layer roughness.
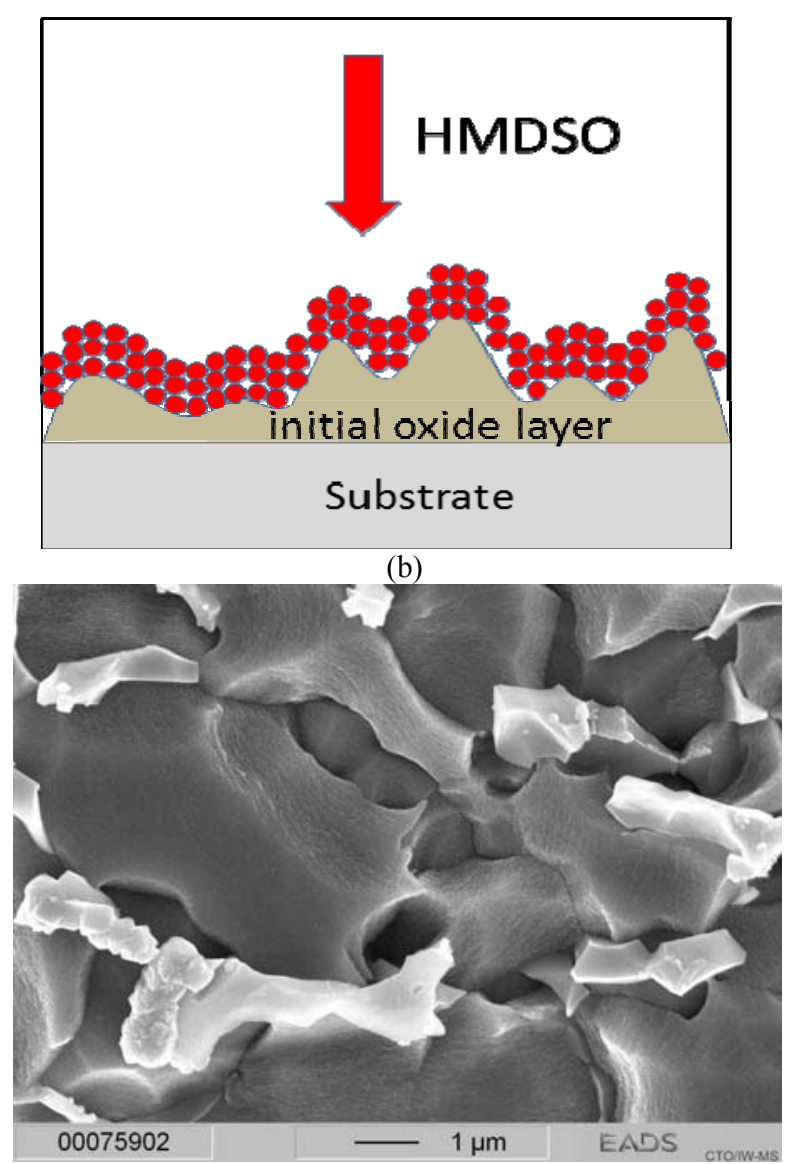

(d)

Fig. 8 Simplified sketch of the structure of different layers created on titanium substrates after alkaline etching step and HMDSO deposition. Red circels are the deposited plasma layer: (a) $\mathrm{Ti}_{15} \mathrm{~V}_{3} \mathrm{Cr}_{3} \mathrm{Sn}_{3} \mathrm{Al}$ alloy, (b) $\mathrm{Ti}_{6} \mathrm{Al}_{4} \mathrm{~V}$ alloy, (c) $\mathrm{SEM}$ micrograph of Ti15V3Cr3Sn3Al after treatment with Turco 5578 (top view) and (d) SEM micrograph of $\mathrm{Ti}_{6} \mathrm{Al}_{4} \mathrm{~V}$ after treatment with Turco 5578 (top view). 

Organosilicon Films for Adhesion Promotion on $\mathrm{Ti}_{15} \mathrm{~V}_{3} \mathrm{Cr}_{3} \mathrm{Sn}_{3} \mathrm{Al}$ and $\mathrm{Ti}_{6} \mathrm{Al}_{4} \mathrm{~V}$

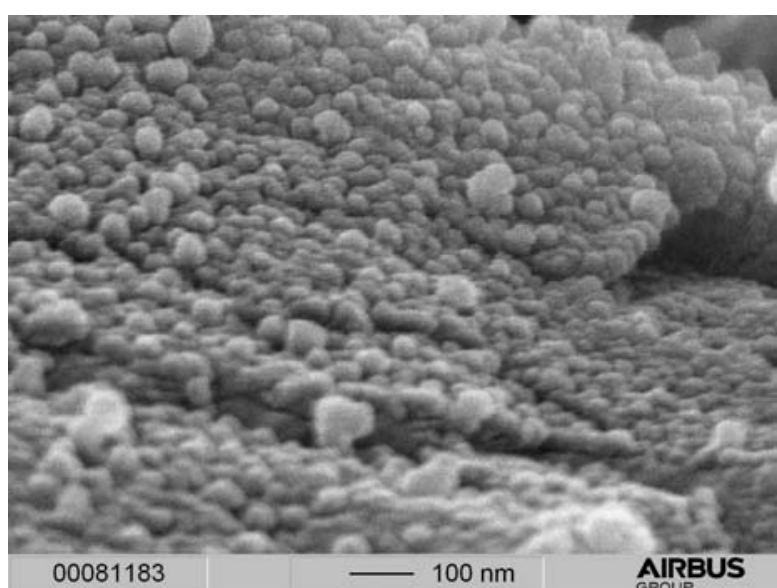

(a)

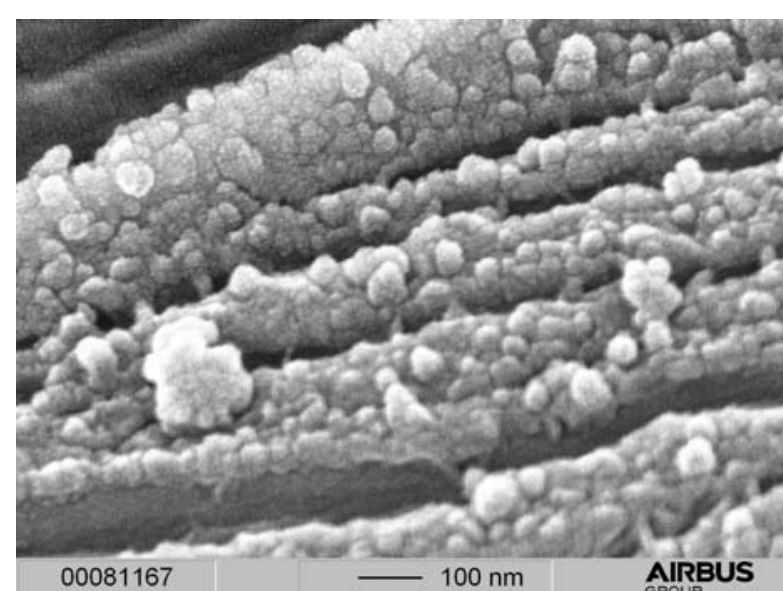

(b)

Fig. 9 SEM micrograph of HMDSO derived plasma layer on titanium alloys (cryo fracture): (a) $\mathrm{Ti}_{6} \mathrm{Al}_{4} \mathrm{~V}$ alloy and (b) $\mathrm{Ti}_{15} \mathrm{~V}_{3} \mathrm{Cr}_{3} \mathrm{Sn}_{3} \mathrm{Al}$.

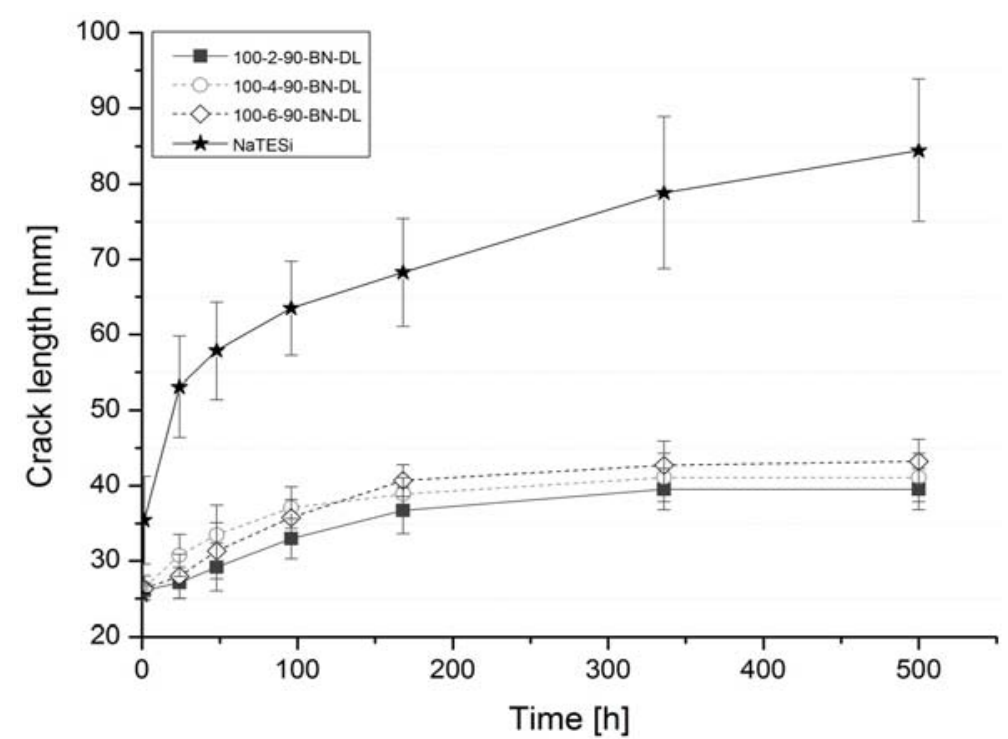

Fig. 10 Wedge test results for $\mathrm{Ti}_{15} \mathrm{~V}_{3} \mathrm{Cr}_{3} \mathrm{Sn}_{3} \mathrm{Al}$ treated with $\mathrm{BN}$ gas feeding system using compressed air (DL, i.e. Druckluft) as processing gas in comparison to anodizing process NaTESi. The legend features the process variations in the following manner: nominal coating thickness-working distance-treatment angle.

\subsection{Investigation of the Bonding Durability}

To evaluate the long-term durability of the plasma treated titanium samples in comparison to a wet-chemical treatment (NaTESi anodizing) the wedge test is used. All treatments lead to a comparable initial crack length and bonding strength, respectively. The initial crack length was for all treatments between 25 and $27 \mathrm{~mm}$. Due to this, for all joints the initial failure locus was similar. The failure was initiated cohesively in the middle of the adhesive.

Fig. 10 presents the wedge test results for
$\mathrm{Ti}_{15} \mathrm{~V}_{3} \mathrm{Cr}_{3} \mathrm{Sn}_{3} \mathrm{Al}$. The specimen treated with $100 \mathrm{~nm}$ nominal thickness at $2 \mathrm{~cm}$ and $4 \mathrm{~cm}$ respectively. $6 \mathrm{~cm}$ working distance features a very good long term durability in comparison to the NaTESi process. All parameters feature a final crack length between $39.5-43.5 \mathrm{~mm}$. After $500 \mathrm{~h}$ exposure to $95 \% \mathrm{rh}$ and $50{ }^{\circ} \mathrm{C}$ the titanium samples anodized with the NaTESi process feature a crack growth of $84.4 \pm 9.4 \mathrm{~mm}$. The results demonstrate that crack propagation after the different plasma treatments is lower compared to the NaTESi anodising. These results confirm that compressed air can be used for the plasma deposition 


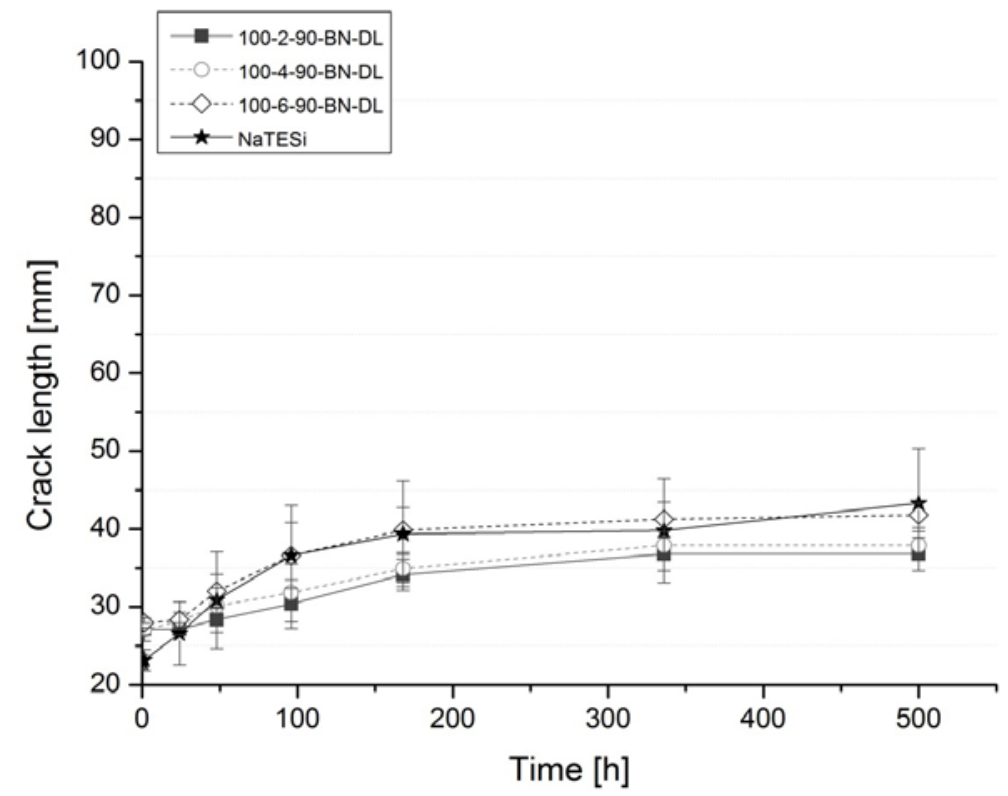

Fig. 11 Wedge test results for $\mathrm{Ti}_{6} \mathrm{Al}_{4} \mathrm{~V}$ treated with $\mathrm{BN}$ gas feeding system using compressed air (DL) as processing gas in comparison to anodizing process NaTESi. The legend features the process variations in the following manner: nominal coating thickness-working distance-treatment angle.

on $\mathrm{Ti}_{15} \mathrm{~V}_{3} \mathrm{Cr}_{3} \mathrm{Sn}_{3} \mathrm{Al}$. Moreover the results show that the working distance can be varied from 2-6 cm on $\mathrm{Ti}_{15} \mathrm{~V}_{3} \mathrm{Cr}_{3} \mathrm{Sn}_{3} \mathrm{Al}$.

Also the long-term durability of bonded $\mathrm{Ti}_{6} \mathrm{Al}_{4} \mathrm{~V}$ samples has been investigated. The wedge test results are shown in Fig. 11. The adhesion results of samples treated with NaTESi anodizing process feature a crack length of $43.5 \pm 7.1 \mathrm{~nm}$. The specimens treated by plasma lead to a crack growth between $36.8 \pm 2.1 \mathrm{~nm}$ and $41.5 \pm 1.6 \mathrm{~nm}$. In summary, all plasma parameter leads to results which are comparable to the reference anodizing process NaTESi or even better for $\mathrm{Ti}_{6} \mathrm{Al}_{4} \mathrm{~V}$ alloy. Likewise to $\mathrm{Ti}_{15} \mathrm{~V}_{3} \mathrm{Cr}_{3} \mathrm{Sn}_{3} \mathrm{Al}$ the results confirm that compressed air can be used for the plasma deposition on $\mathrm{Ti}_{6} \mathrm{Al}_{4} \mathrm{~V}$. Moreover the results show that the working distance can be varied from $2-6 \mathrm{~cm}$ on $\mathrm{Ti}_{6} \mathrm{Al}_{4} \mathrm{~V}$.

As shown in Fig. 9, $\mathrm{Ti}_{6} \mathrm{Al}_{4} \mathrm{~V}$ and $\mathrm{Ti}_{15} \mathrm{~V}_{3} \mathrm{Cr}_{3} \mathrm{Sn}_{3} \mathrm{Al}$ feature a different surface morphology after plasma deposition. The adhesion behavior of titanium alloys depends on the morphology and surface chemistry of the deposited film. The chemical composition of the deposited plasma film and it dependence on the long-term stability of bonded titanium joints is described in previous publications $[3,11]$. The wedge test results obtained confirm the correlation between the morphology of the adhesion promotion layer and adhesive bond strength. $\mathrm{Ti}_{6} \mathrm{Al}_{4} \mathrm{~V}$ samples show a slightly lower crack length of $38.6 \pm 1.8 \mathrm{~nm}$, due to the large amount of nano roughness compared to the $\mathrm{Ti}_{15} \mathrm{~V}_{3} \mathrm{Cr}_{3} \mathrm{Sn} 3 \mathrm{Al}$ samples with the crack length of 41.3 $\pm 2.9 \mathrm{~nm}$.

\section{Conclusions}

The results of this work show that the atmospheric pressure plasma deposition of adhesion promoting layer from HMDSO as precursor using long arc generator plasma source (LARGE) is a promising surface pre-treatment technique to improve a good long-term adhesion on titanium alloys.

It has been demonstrated that the titanium $\beta$ - alloy $\mathrm{Ti}_{15} \mathrm{~V}_{3} \mathrm{Cr}_{3} \mathrm{Sn}_{3} \mathrm{Al}$ and the $\alpha+\beta$ - alloy $\mathrm{Ti}_{6} \mathrm{Al}_{4} \mathrm{~V}$ show a different degree of micro roughness after alkaline etching by Turco 5578. The initial oxide layer morphology has a strong influence on the homogeneity and porosity of the deposited HMDSO plasma layer. However, the degree of nano roughness and the thickness of the silicon dioxide layer have 

Organosilicon Films for Adhesion Promotion on $\mathrm{Ti}_{15} \mathrm{~V}_{3} \mathrm{Cr}_{3} \mathrm{Sn}_{3} \mathrm{Al}$ and $\mathrm{Ti}_{6} \mathrm{Al}_{4} \mathrm{~V}$

nearly the same value for both alloys.

The obtained wedge test results underline the correlation between the durability of adhesion bonds and the surface morphology of the adhesion promoting layer. The higher degree of micro roughness on $\mathrm{Ti}_{6} \mathrm{Al}_{4} \mathrm{~V}$ alloy results in a better long-term durability of the bonded samples in comparison to the smooth surface of the bonded $\mathrm{Ti}_{15} \mathrm{~V}_{3} \mathrm{Cr}_{3} \mathrm{Sn}_{3} \mathrm{Al}$ samples.

\section{Acknowledgments}

Financial support of the EC (FP7 framework, Pliant-Process Line Implementation for Applied Surface Nanotechnologies, agreement number 309530) is gratefully acknowledged.

\section{References}

[1] Arefi, F., Andre, V., Montazer-Rahmati, P. and Amouroux, J. 1992. "Plasma Polymerization and Surface Treatment of Polymers." Pure and Applied Chemistry 64 (5): 715-23.

[2] Hegemann, D., Vohrer, U., Oehr, C. and Riedel, R. 1999. "Deposition of SiOx Films from O2/HMDSO Plasmas." Surf. Coatings Technol. 116-9: 1033-6.

[3] Kotte, L., Althues, H., Mäder, G., Roch, J., Kaskel, S. and Dani, I. et al. 2013. "Atmospheric Pressure PECVD Based on a Linearly Extended DC arc for Adhesion Promotion Applications." Surf. Coatings Technol. 234: 8-13.

[4] Ratner, B. D., Chilkoti, A. and Lopez, G. P. 1990. Plasma Deposition, Treatment, and Etching of Polymers.
San Diego.

[5] Kurosawa, S., Choi, B. G., Park, J. W., Aizawa, H., Shim, K. B. and Yamamoto, K. 2006. "Synthesis and Characterization of Plasma-Polymerized Hexamethyldisiloxane Films." Thin Solid Films 506-7: 176-9.

[6] Gammon, L. M., Briggs, R. D., Packard, J. M., Batson, K. W., Boyer, R. and Domby, C. W. 2004. "Metallography and Microstructures of Titanium and its Alloys." Mater. Park. OH ASM Int., 899-917.

[7] Peters M. and Leyens, C. 2002. Titan und Titanlegierungen. Auflage. Weinheim, Germany: Wiley-VCH Verlag GmbH \& Co. KGaA.

[8] Lütjering, G., Williams, J. C. and Gysler, A. 2000. "Microstructure and Mechanical Properties of Titanium Alloys." Microstruct. Prop. Mater. 2: 1-74.

[9] Matz, C. 1988. "Optimization of the Durability of Structural Titanium Adhesive Joints." Int. J. Adhes. Adhes. 8 (1): 17-24.

[10] Hartmann, R., Kraut, G. and Landes, K. 1999. “CIPASS An Ignition Method for the Innovative Plasma Torch 'LARGE'." The European Physical Journal Applied Physics 8: 253-6.

[11] Kotte, L., Haag, J., Mertens, T. and Kaskel, S. 2014. "Atmospheric Plasma Deposition of $\mathrm{SiO}_{2}$ Films for Adhesion Promoting Layers on Titanium." Metals (Basel). 4 (4): 639-46.

[12] Hopfe, V., Rogler, D., Maeder, G., Dani, I., Landes, K. and Theophile, E. et al. 2005. "Linear Extended ArcJet-CVD - A New PECVD Approach for Continuous Wide Area Coating under Atmospheric Pressure." Chem. Vap. Depos. 11 (11-12): 510-22.

[13] Ratsch C. and Venables, J. A. 2003. "Nucleation Theory and the Early Stages of Thin Film Growth." J. Vac. Sci. Technol. A Vacuum, Surfaces, Film 21: S96.

[14] Venables, J. A. 1983. "Nucleation and Growth of Thin Films: Recent Progress." Vacuum 33: 701-5. 